Research Note-

\title{
Reproduction of Fowl Typhoid by Respiratory Challenge with Salmonella Gallinarum
}

\author{
Hom Bahadur Basnet, Hyuk-Joon Kwon, ${ }^{A}$ Sun-Hee Cho, Sun-Joong Kim, Han-Sang Yoo, Yong-Ho Park, Seong-Il Yoon, \\ Nam-Sik Shin, and Hee-Jeong Youn
}

Zoonotic Disease Institute (ZooDI), College of Veterinary Medicine, Seoul National University, Seoul 151-742, Korea

Received 26 March 2007; Accepted and published ahead of print 17 September 2007

\begin{abstract}
SUMMARY. Fowl typhoid is a disease of adult chickens and is caused by Salmonella Gallinarum infection via the alimentary tract. The experimental reproduction of fowl typhoid per os $(P O)$ requires artificial conditions to minimize the effect of gastric acid, and several Salmonella serovars have been known to be transmitted via the respiratory route. Therefore, we have hypothesized the existence of a respiratory route for Salmonella Gallinarum infection and have attempted to reproduce fowl typhoid via intratracheal challenge. In accordance with our hypothesis, the intratracheal challenges of Salmonella Gallinarum reproduced exactly same lesions as fowl typhoid and induced higher mortality and morbidity than those of the $P O$ challenge. Therefore, this study represents the first reproduction of fowl typhoid via respiratory route, and our findings may be useful for understanding the transmission of Salmonella Gallinarum in the field.
\end{abstract}

RESUMEN. Nota de Investigación-Reproducción de la Tifoidea Aviar mediante desafío respiratorio con Salmonella Gallinarum. La tifoidea aviar es una enfermedad de las aves adultas causada por la infección con Salmonella Gallinarum por la vía del tracto alimenticio. La reproducción experimental de la tifoidea aviar por la vía oral requiere unas condiciones artificiales que minimicen el efecto de los ácidos gástricos, y se sabe que varios serovares de Salmonella pueden ser transmitidos por vía respiratoria. Por consiguiente, hemos postulado la existencia de una ruta respiratoria para la infección con Salmonella Gallinarum y hemos intentado reproducir la tifoidea aviar vía desafío intratraqueal. De acuerdo con esta hipótesis, los desafíos intratraqueales de Salmonella Gallinarum reprodujeron exactamente las mismas lesiones provocadas por la enfermedad e indujeron mayor mortalidad y morbilidad que aquellas que fueron desafiadas por la vía oral. Este estudio representa la primera reproducción de la tifoidea aviar por vía respiratoria y los hallazgos pueden ser útiles para entender la transmisión de Salmonella Gallinarum en el campo.

Key words: fowl typhoid, Salmonella Gallinarum, intratracheal challenge

Abbreviations: $\mathrm{cfu}=$ colony-forming unit; $\mathrm{ck}=$ chick; DPI $=$ day postinoculation; BALT = bronchus-associated lymphoid tissue; GALT = gut-associated lymphoid tissue; LB = Luria-Bertani broth; MALT = mucosa-associated lymphoid tissues; $\mathrm{PO}=$ per os $($ oral)

Fowl typhoid is mainly an acute, septicemic disease of adult chickens, characterized by anemia, leukocytosis, and hemorrhage (25). Fowl typhoid is a disastrous disease in the poultry industry not only because of its ability to cause enormous economic losses but also because of its extreme difficulty in eradication. The causative agent, Salmonella enterica serovar Gallinarum, is both nonmotile and host adapted and rarely induces food poisoning in humans $(1,21)$. The alimentary tract is the normal route of Salmonella infection, and the mechanisms underlying this infection route have been well established by studies on Salmonella Typhimurium $(4,7,10,11,16$, 17). Alternative Salmonella infection routes have long been suspected, and systemic infections of Salmonella Enteritidis PT4 and Salmonella Typhimurium DT104 via the respiratory route have been reported previously $(3,17)$. Pneumonia has been reported from intranasal challenge with Salmonella Choleraesuis $(2,12)$. For the experimental reproduction of fowl typhoid via the oral (per os, PO) route, relatively high titers of Salmonella are required, and a special inoculum preparation is required to reduce the effects of gastric juice (23). In addition, a variety of intestinal microflora may reduce the viable number of challenged and secreted Salmonella (8). On the basis of the reports on the respiratory infection of other Salmonella serovars and our experience with rapid transmission of fowl typhoid in some field cases, which supports airborne transmission and fluctuation of results in reproduction of the disease via PO challenge,

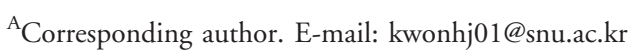

we hypothesized the respiratory infection of fowl typhoid. Although fowl typhoid is a disease of adult chickens, experimental fowl typhoid can be reproduced in chicks by $P O$ challenge of Salmonella Gallinarum (14). Young chicks are usually reared on the floor, and they have many chances to inhale dusts that might be contaminated by feces containing Salmonella Gallinarum. Therefore, to demonstrate Salmonella Gallinarum infection via the respiratory route, we challenged several age groups of chicks via the oral and intratracheal routes with Salmonella Gallinarum and compared the mortality and morbidity of the experimental groups.

\section{MATERIALS AND METHODS}

Bacteria. A strain of Salmonella Gallinarum, SNU0197, was isolated from broiler chickens consigned to diagnosis in 2000 and was identified as previous described (19). SNU0197 was grown in brilliant-green agar (Difco, Detroit, MI), supplemented with novobiocin $(20 \mu \mathrm{g} / \mathrm{ml}$; SigmaAldrich Co., St. Louis, MO), and a single colony was grown in LuriaBertani (LB) broth.

Animal experiments. Five independent animal experiments were conducted using different age groups, chicken breeds, and inoculum titers: male Hy-Line brown layer (1-, 7-, and 8-day-old) and broiler (Ross, 16-day-old) chicks, and variable inoculum titers from $1.0 \times 10^{2}$ to $3.39 \times 10^{6} \mathrm{cfu} /$ chick (Table 1 ). We determined the challenge dose on the basis of our unpublished experimental data. The dose of $10^{6} \mathrm{cfu} /$ chick (ck) caused mortality of 7-day-old, male brown-layer chicks from $50 \%$ to $100 \%$ without treatment of antiacid reagents. Because we expected respiratory route was more sensitive than the $P O$ route, we 
Table 1. Comparison of intratracheal (IT) and per os $(P O)$ challenges with Salmonella Gallinarum.

\begin{tabular}{|c|c|c|c|c|c|}
\hline Age chicken & Route & Dose (cfu/ck) & Mortality & Reisolation & Lesions $^{\mathrm{A}}$ \\
\hline \multirow[t]{2}{*}{ 1-day-old layer ${ }^{\mathrm{B}}$} & IT & $1.0 \times 10^{2}$ & $20.0 \%(2 / 10)$ & $20.0 \%(2 / 10)$ & $\begin{array}{l}\text { hmnf }(7 / 10) ; \text { sm }(8 / 10) ; \text { hfs }(4 / 10) \\
\text { np }(6 / 10) ; \text { pn }(2 / 10)\end{array}$ \\
\hline & $P O$ & $1.0 \times 10^{2}$ & $10.0 \%(1 / 10)$ & $10.0 \%(1 / 10)$ & hmnf (5/10); sm (6/10); np (6/10) \\
\hline \multirow{3}{*}{ 7-day-old layer } & PO & $5.75 \times 10^{3}$ & $6.7 \%(1 / 15)$ & $33.3 \%(5 / 15)$ & hm (1/15); hmnf (2/15); sm (1/15) \\
\hline & IT & $5.75 \times 10^{5}$ & $66.7 \% *(10 / 15)$ & $80 \%(8 / 10)$ & hmnf (10/10); sm (10/10) \\
\hline & PO & $5.75 \times 10^{5}$ & $20.0 \%(3 / 15)$ & $71.4 \%(5 / 7)$ & hm (5/15); hmnf (6/15) \\
\hline \multirow[t]{2}{*}{ 16-day-old broiler ${ }^{\mathrm{C}}$} & IT & $3.39 \times 10^{6}$ & $30 \%(3 / 10)$ & $100 \%(10 / 10)$ & $\begin{array}{l}\text { hmnf (10/10); sm (10/10); hpc (10/10); } \\
\quad \text { nmh (6/10); bl }(6 / 10)\end{array}$ \\
\hline & $P O$ & $3.39 \times 10^{6}$ & $30 \%(3 / 10)$ & $60.0 \%(6 / 10)$ & hm $(4 / 10) ;$ sm $(4 / 10)$ \\
\hline
\end{tabular}

${ }^{\mathrm{A}}$ Abbreviations: hmnf = hepatomegaly with necrotic foci; $\mathrm{sm}=$ splenomegaly; hfs = hemorrhagic foci on spleen; np = nephrosis; pn = pneumonia; $\mathrm{hm}=$ hepatomegaly; hpc = hydropericardium; $\mathrm{nmh}=$ nodular mass on the heart; $\mathrm{bl}=$ bronze liver.

${ }^{\mathrm{B}}$ Hy-Line, brown, male chickens.

CRoss.

*Significant $(P<0.05)$ difference compared with the corresponding $P O$ group.

reduced the challenge dose by 10 -fold for dramatic contrast of mortality and morbidity between the routes. With 1-day-old chicks, we simply tested whether or not the dose of $1.0 \times 10^{2} \mathrm{cfu} / \mathrm{ck}$ caused fowl typhoid. We used male layer chicks that were negative for Salmonella Gallinarum in the experiments so that we could follow the health condition of female chicks from the same batches on farms. Therefore, we didn't include an additional negative-control group under consideration of animal welfare. Salmonella Gallinarum-negative chicks were verified via plate-agglutination tests (SP antigen; Intervet Co., Boxmeer, the Netherlands).

In each experiment, chicks were divided into two groups by the route of challenge, intratracheal and $P O$. For intratracheal inoculation, $5 \mu \mathrm{l}$ of inoculum was obtained with a micropipette, and the tip end was inserted and injected slowly into the trachea of chicks in the intratracheal group. An identical amount was used to inoculate chicks in the $P O$ group. Clinical signs and mortality were monitored for 10 days, and all of the live chicks were sacrificed at the 11th day-postinoculation (DPI). Lesions were observed and Salmonella Gallinarum was isolated from the liver, kidney, spleen, and cecal feces, using brilliant-green agar plates with novobiocin directly or after enrichment in peptone broth (Difco) and successive selective growth in 10-fold quantity of RappaportVassiliadis R10 broth (Difco) for $24 \mathrm{hr}$ at $42 \mathrm{C}$.

Analysis of data. The relationship between the infection route and mortality was evaluated via chi-square and Fisher exact tests $(95 \%$ confidence interval), using SPSS for Windows, Version 12.0.

\section{RESULTS}

Reproduction of fowl typhoid in chickens. In a preliminary study, 1-day old, male brown-layer chicks were challenged with 1.0 $\times 10^{2} \mathrm{cfu} / \mathrm{ck}$ via intratracheal and $P O$ routes. The mortality of the intratracheal group was $20 \%(2 / 10)$ and the mortality of the $P O$ group was $10 \%(1 / 10)$ at 6 DPI (Table 1$)$. In the intratracheal group, the live chicks evidenced hepatomegaly with necrotic foci $(5 /$ $8)$, splenomegaly $(6 / 8)$, hemorrhagic foci on the spleen $(2 / 8)$, and slight nephrosis (4/8). All of the dead chicks (2/2) evidenced lesions identical to those of the live chicks, coupled with pneumonia. In the $P O$ group, the live chicks evidenced hepatomegaly with necrotic foci in the liver (4/9), splenomegaly (5/9), and nephrosis (5/9). The dead chicks evidenced the same lesions as the live chicks. Salmonella Gallinarum was recovered from all of the dead chicks in both groups (Table 1).

Seven-day-old, male brown-layer chicks were challenged with $5.75 \times 10^{3} \mathrm{cfu} / \mathrm{ck}$ via intratracheal and $P O$ routes. In the intratracheal group, mortality was $13 \%(2 / 15)$, and mortality in the $P O$ group was $6.7 \%(1 / 15)$ at $10 \mathrm{DPI}$ (Table 1$)$. In the intratracheal group, both the dead chicks $(2 / 2)$ and live chicks evidenced hepatomegaly and splenomegaly (2/13). Salmonella Gallinarum was recovered from $80 \%$ of the liver samples $(8 / 10$; Table 1). In the $P O$ group, the dead chicks exhibited splenomegaly and hepatomegaly. The live chicks evidenced hepatomegaly with necrotic foci $(2 / 14 ; 14 \%)$. Salmonella Gallinarum was recovered from $33.3 \%(5 / 15)$ of the liver samples (Table 1$)$. Seven-day-old, male brown-layer chicks were challenged with $5.75 \times 10^{5} \mathrm{cfu} / \mathrm{ck}$, via intratracheal and $P O$ routes; $66.7 \%(10 / 15)$ and $20 \%$ of mortalities were observed in the intratracheal and the $P O$ groups (3/ $15)$, respectively. In the intratracheal group, all of the live chicks evidenced hepatomegaly with necrotic foci $(5 / 5)$ and splenomegaly (5/5), and the five dead and necropsied chicks evidenced the same lesions. Salmonella Gallinarum was recovered from $80 \%$ of the liver samples $(8 / 10)$ (Table 1$)$. In the $P O$ group, the live chicks exhibited hepatomegaly $(16.7 \% ; 2 / 12)$ and liver necrotic foci $(25 \% ; 3 / 12)$, and all of the dead chicks manifested the same lesions. Salmonella Gallinarum was recovered from $71.4 \%$ of the liver samples $(5 / 7)$. The mortality of intratracheal group was significantly higher than that of the $P O$ group $(P<0.05, P=0.025$; Table 1$)$.

Eight-day-old, male brown-layer chicks were challenged with 1.16 $\times 10^{5} \mathrm{cfu} / \mathrm{ck}$, via intratracheal and $P O$ routes; $73 \%$ and $0 \%$ of mortalities were observed in the intratracheal and the $P O$ groups, respectively. In the intratracheal group, the live chicks evidenced splenomegaly $(100 \% ; 4 / 4)$ and hepatomegaly with necrotic foci $(100 \% ; 4 / 4)$, and all of the dead chicks evidenced the same lesions. Salmonella Gallinarum was recovered from all of the liver samples (Table 1). In the $P O$ group, the live chicks evidenced mild splenomegaly $(20 \% ; 3 / 15)$ and mild hepatomegaly with necrotic foci $(40 \%$; 6/15). Salmonella Gallinarum was recovered from $20 \%$ of the liver samples, and the intratracheal group manifested significantly higher mortality than the $P O$ group $(P<0.05, P=0.000)$ (Table 1).

To reproduce fowl typhoid in broiler chickens, 16-day-old broilers were challenged with $3.39 \times 10^{6} \mathrm{cfu} / \mathrm{ck}$ via intratracheal and $P O$ routes. Mortality was $30 \%$ in both the intratracheal and $P O$ groups $(3 / 10)$. In the intratracheal group, the live chicks evidenced splenomegaly $(100 \%$; $7 / 7)$, hepatomegaly with necrotic foci $(100 \%$; $7 / 7)$, hydropericardium $(100 \% ; 7 / 7)$, nodular masses on the heart $(42.9 \% ; 3 / 7)$, and bronze liver $(42.9 \% ; 3 / 7)$, and all of the dead 
chicks manifested the same lesions. Salmonella Gallinarum was recovered from all of the liver samples $(100 \% ; 10 / 10)$. In the $P O$ group, the live chicks evidenced splenomegaly $(14.3 \%$; $1 / 7)$ and hepatomegaly $(14.3 \% ; 1 / 7)$, and all of the dead chicks showed the same lesions. Salmonella Gallinarum was recovered from $60 \%$ of the liver samples (6/10; Table 1). Salmonella Gallinarum was isolated from the cecal contents of all of the dead chicks. The cecal contents of the live chicks were $100 \%(3 / 3)$ and $33 \%(1 / 3)$ positive in the intratracheal and the $P O$ groups, respectively, after enrichment with Rappaport-Vassiliadis R10 broth.

\section{DISCUSSION}

The hydrochloric acid in the stomach performs a pivotal function in protecting the body against pathogens ingested with food or water (24). The experimental reproduction of fowl typhoid in adult chickens via oral Salmonella Gallinarum challenge is quite difficult and requires a very high titer of Salmonella Gallinarum as well as treatment of Salmonella Gallinarum with some reagents to reduce the effects of gastric juice (23). This inherent difficulty in the reproduction of fowl typhoid has been an obstacle to the experimental evaluation of vaccines as well as our understanding of fowl typhoid outbreaks in the field. According to the results of the present study, fowl typhoid was reproducible in the 1-day-old brown-layer chicks via intratracheal inoculation at only $100 \mathrm{cfu} / \mathrm{ck}$, and several thousand $\mathrm{cfu} / \mathrm{ck}$ proved sufficient to infect $80 \%$ of the 7 -day-old chicks. The intratracheal route was more effective than the oral route in terms of mortality and morbidity, and the two inoculation routes differed significantly in terms of mortality $(P<0.05)$.

Respiratory inoculation of Salmonella Enteritidis or Salmonella Typhimurium induced systemic infection (10,11). Salmonella Choleraesuis inoculated via the intranasal route also induced systemic infection, but pneumonia was the principal clinical and pathologic finding in the challenged pigs $(2,12,26)$. In addition, oral Salmonella Choleraesuis inoculation typically resulted in enterocolitis and septicemia (17). In cases of the pullorum disease induced by Salmonella Pullorum, respiratory signs, such as labored breathing or gasping, may be observed as the result of extensive involvement of the lungs; however, whether the lung involvement is primary or secondary remains unclear (22). The majority of chicks intratracheally challenged with Salmonella Gallinarum evidenced septicemic lesions without pneumonia, except for several 1-day-old chicks, and we were unable to detect any pathologic differences between the two inoculation routes. According to the mortality and the titer of inoculum, broiler chicks seemed to be more resistant to fowl typhoid than brown layers, but to demonstrate breed-dependent resistance to fowl typhoid, further studies are required $(5,22)$.

In the alimentary tract, the ileal $\mathrm{M}$ cells of mice function as a portal for the entrance of Salmonella Typhimurium and Salmonella Typhi but not for Salmonella Gallinarum (20). Salmonella Pullorum preferentially invaded an organized lymphoid tissue, the bursa of Fabricius, instead of targeting intestinal epithelium, but Salmonella Gallinarum didn't show any preference for the bursa of Fabricius over jejunum and caecal tonsils $(6,13)$. The phenotype and function of $\mathrm{M}$ cells on gut-associated lymphoid tissue (GALT) of chickens were less distinguishable from epithelial cells than is seen in mammals, and the epithelial cells in chicken bronchus-associated lymphoid tissue (BALT) lacked M-cell type cells $(9,15)$. Therefore, Salmonella Gallinarum is likely to penetrate through both $\mathrm{M}$ cells and epithelial cells on GALT and epithelial cells on BALT to infect lymphoid cells. In the present study, we have successfully reproduced fowl typhoid via intratracheal Salmonella Gallinarum challenge, and the respiratory route was determined to be more effective than the alimentary route. Therefore, the respiratory route should be considered one of the alternative pathways of Salmonella Gallinarum infection, and further studies regarding the respiratory transmission of fowl typhoid in the field are urgently required.

\section{REFERENCES}

1. Barrow, P. A., M. B. Huggins, and M. A. Lovell. Host specificity of Salmonella infection in chickens and mice is expressed in vivo primarily at the level of the reciculoendothelial system. Infect. Immun. 62:4602-4610. 1994.

2. Baskerville, A., and C. Dow. Pathology of experimental pneumonia in pigs produced by Salmonella Choleraesuis. J. Comp. Pathol. 83:207-215. 1973.

3. Baskerville, A., T. J. Humphrey, R. B. Fitzgeorge, R. W. Cook, H. Chart, B. Rowe, and A. Whitehead. Airborne infection of laying hens with Salmonella Enteritidis phage type 4. Vet. Rec. 130:395-398. 1992.

4. Bliska, J. B., J. E. Galan, and S. Falkow. Signal transduction in the mammalian cell during bacterial attachment and entry. Cell 73:903-920. 1993.

5. Bumstead, N., and P. Barrow. Resistance to Salmonella Gallinarum, Salmonella Pullorum, and Salmonella Enteritidis in inbred lines of chickens. Avian Dis. 37:189-193. 1993.

6. Chadfield, M. S., D. J. Brown, S. Aabo, J. P. Christensen, and J. E. Olsen. Comparison of intestinal invasion and macrophage response of Salmonella Gallinarum and other host-adapted Salmonella enterica serovars in the avian host. Vet. Microbiol. 92:49-64. 2003.

7. Clark, M. A., M. A. Jepson, N. L. Simmons, and B. H. Hirst. Preferential interaction of Salmonella Typhimurium with mouse Peyer patch M cells. Res. Microbiol. 145:543-552. 1994.

8. Collins, F. M., and P. B. Carter. Growth of Salmonellae in orally infected germ-free mice. Infect. Immun. 21:41-47. 1978.

9. Fagerland, J. A., and L. H. Arp. Structure and development of bronchus-associated lymphoid tissue in conventionally reared broiler chickens. Avian Dis. 37:10-18. 1993.

10. Francis, C. L., T. A. Ryan, B. D. Jones, S. J. Smith, and S. Falkow. Ruffles induced by Salmonella and other stimuli direct macropinocytosis of bacteria. Nature 364:639-642. 1993.

11. Ginocchio, C., J. Pace, and J. E. Galan. Identification and molecular characterization of a Salmonella Typhimurium gene involved in triggering the internalization of salmonellae into cultured epithelial cells. Proc. Nat. Acad. Sci. U. S. A. 89:5976-5980. 1992.

12. Gray, J. T., P. J. Fedorka-Cray, T. J. Stabel, and M. R. Ackermann. Influence of inoculation route on the carrier state of Salmonella Choleraesuis in swine. Vet. Microbiol. 47:43-59. 1995.

13. Henderson, S. C., D. I. Bounous, and M. D. Lee. Early events in the pathogenesis of avian salmonellosis. Infect. Immun. 67:3580-3586. 1999.

14. Hill, R., and I. M. Smith. The influence of protein source and basal dietary component on survival in acute experimental fowl typhoid in the chick (Gallus domesticus). Br. J. Nutr. 38:471-478. 1977.

15. Jeurissen, S. H. M., F. Wagenaar, and E. M. Janse. Further characterization of $\mathrm{M}$ cells in gut-associated lymphoid tissues of the chicken. Poult. Sci. 78:965-972. 1999.

16. Jones, B. D., N. Ghori, and S. Falkow. Salmonella Typhimurium initiates murine infection by penetrating and destroying the specialized epithelial M cells of the Peyer patches. J. Exp. Med. 180:15-23. 1994.

17. Lawson, G. H. K., and C. Dow. The pathogenesis of oral Salmonella Choleraesuis infection in pigs. J. Comp. Path. 75:75-81. 1965.

18. Leach, S. A., A. Williams, A. C. Davies, J. Wilson, P. D. Marsh, and T. J. Humphrey. Aerosol route enhances the contamination of intact eggs and muscle of experimentally infected laying hens by Salmonella Typhimurium DT104. FEMS Microbiol. Lett. 171:203-207. 1999.

19. Park, K. Y., S. U. Lee, H. S. Yoo, and J. K. Yeh. Epidemiological studies of Salmonella Gallinarum infection in Korea: infection routes, biochemical characteristics, antimicrobial drug susceptibility pattern and plasmid profile. Korean J. Infect. Dis. 28:413-421. 1996. 
20. Pascopella, L., B. Raupach, N. Ghori, D. Monack, S. Falkow, and P. L. C. Small. Host restriction phenotypes of Salmonella Typhi and Salmonella Gallinarum. Infect. Immun. 63:4329-4335. 1995.

21. Pomeroy, B. S. Fowl typhoid. In: Diseases of poultry, 9th ed. B. W. Calnek, H. J. Barnes, C. W. Beard, W. M. Reed, and J. H. W. Yoder, eds. Iowa State University Press, Ames, IA. p. 571. 1991.

22. Shivaprasad, H. L. Pullorum disease and fowl typhoid. In: Diseases of poultry, 11th ed. Y. M. Saif, H. J. Barnes, A. M. Fadly, J. R. Glisson, L. R. McDougald, and D. E. Swayne, eds. Iowa State University Press, Ames, IA. p. 571.2005.

23. Smith, H. W. The use of live vaccines in experimental Salmonella Gallinarum infection in chickens with observation on their interference effect. J. Hyg. 54:419-432. 1956.

24. Smith, J. L. The role of gastric acid in preventing foodborne disease and how bacteria overcome acid conditions. J. Food Prot. 66:1292-1303. 2003.
25. Snoeyenbos, G. H. Pullorum disease. In: Diseases of poultry, 9th ed. B. W. Calnek, H. J. Barnes, C. W. Beard, W. M. Reed, and J. H. W. Yoder, eds. Iowa State University Press, Ames, IA. p. 571. 1991.

26. Turk, J. R., W. H. Fales, C. Maddox, M. Miller, L. Pace, J. Fischer, J. Kreeger, G. Johnson, S. Turnquist, and J. A. Ramos. Pneumonia associated with Salmonella Choleraesuis infection in swine: 99 cases (1987-1990). J. Am. Vet. Med. Assoc. 201:1615-1616. 1992.

\section{ACKNOWLEDGMENTS}

This work was supported by a Korea Research Foundation Grant. (KRF-2006-005-J02901 and KRF-2006-005-J02902) and by the Technology Development Program of the Ministry of Agriculture and Forestry, Korea. 